\title{
Study on the Effect of Monochromatic Light on the Growth of the Red Tide Diatom Skeletonema costatum
}

\author{
Hongli Miao, Lina Sun, Qingzhen Tian, Shanshan Wang, Jing Wang \\ College of Information Science and Engineering, Ocean University of China, Qingdao, China \\ Email: wjing@ouc.edu.cn
}

Received June 19, 2012; revised July 21, 2012; accepted August 1, 2012

\begin{abstract}
Effects of light intensity and quality of three kinds of LED monochromatic lights (blue, green, and red) on the growth of Skeletonema costatum are investigated in batch culture conditions. Seven light intensities $(20,30,40,45,50,60$ and 80 $\mu \mathrm{mol} \cdot \mathrm{m}^{-2} \cdot \mathrm{s}^{-1}$ ) are used to evaluate the specific growth rate, spectrum absorption coefficient and saturated light intensity of LED monochromatic light. Results show that the growth rates of Skeletonema costatum increase with the enhanced light intensity; however, the light level beyond the saturation light intensity inhibited the growth of Skeletonema costatum. Compared with red and green light, the growth rate of Skeletonema costatum under blue light is higher within saturated light intensity, and saturated light intensity of LED monochromatic light is lower under blue light and higher under green light. It is concluded that under different monochromatic light, the saturated light intensity decreases and the growth rate increases with the increasing of spectrum absorption coefficient.
\end{abstract}

Keywords: Monochromatic Light; Saturated Light Intensity; Skeletonema costatum; Growth Rate; Red Tide

\section{Introduction}

Under certain ecological conditions, some marine microalgae may grow rapidly in a short time and lead to discoloration of waterbody or water blooms, which refer to harmful algal blooms. Such over-proliferated blooms are harmful to other organisms and other organisms can be affected directly or indirectly [1]. The marine diatom Skeletonema costatum has been considered as one of the dominant red tide species in the coastal areas, and it distributes widely in the waters around the world. In China, it is one of typical seriously harmful red tide species [2]. Many physical factors play important roles in the growth of this harmful alga. Among these factors, light is an important environmental factor which can affect microalgae growth, and it is one of the key environmental factors of the red tides happened [3-6]. For a certain $\mathrm{pH}$ value, temperature, and nutrition conditions, the light intensity and the duration of illumination which decides the algae photosynthesis efficiency also play crucial roles on the growth rate of algae [7-9].

Many studies on the effects of light intensity, temperature and salinity have been reported [10-14]. However, in terms of light intensity, most studies focused on the effects of fluorescent or the sun-light on the growth of red tide species $[10,11]$. Studies of the influence of light on the Skeletonema costatum have been reported by Baiye Sun with filed culture experiments and model calcula- tions [12], and the optimal light intensity for growth of Skeletonema costatum increases gradually to a maximum of $121.6 \mathrm{~W} \cdot \mathrm{m}^{-2}$ with temperature up to $25^{\circ} \mathrm{C}$. Under this temperature, the optimal irradiance was $7000 \mathrm{~lx}$ for Skeletonema costatum reported by Yu Ping [13]. Also, it was described that under the high temperature, Skeletonema costatum adapted to higher light intensity, and under the low temperature conditions it adapted to the low light intensity. The optimal light intensity for growth of Skeletonema costatum was 3000 - 6000 lx reported by Chou Jianbiao [14]. The light source in their studies was white light of fluorescent. However, white light is composed of seven monochromatic lights, in order to determine the role of light wavelength on the growth of Skeletonema costatum and explain the effects of light on the red tides from photosynthesis mechanism, it is necessary to research the effect of the monochromatic light on the growth conditions of Skeletonema costatum. Besides, in the experiment by using the filter to get the beam width of light for monochromatic research, light energy loss is serious, and the beam width of light is relatively large [15-17].

In this work, we use the monochromatic light-emitting diode (LED) as the light source and study the effects of three monochromatic lights on the growth of Skeletonema costatum with the same photosynthetic available quantum flux density. Based on the study on the effects of different wavelength of monochromatic light and different light intensities on the growth of Skeletonema costatum, 
we obtain the saturated light intensities of different monochromatic lights, and further provide the basis of analysis of the mechanism of the red tides occurrence.

\section{Materials and Methods}

\subsection{Algal Species and Culture Conditions}

The strain of Skeletonema costatum is obtained from the Institute of Fisheries College, Ocean University of China. Seawater used in this work is sterilized artificial seawater that is filtered through a $0.45 \mu \mathrm{m}$ filter before used for culture medium preparation. Algal cells in the exponenttial growth phase are used, which are inoculated into 300 $\mathrm{mL}$ Erlenmeyer flasks containing $100 \mathrm{~mL}$ fresh $\mathrm{f} / 2$ enriched seawater. Stock cultures are maintained in sterilized Erlenmeyer flasks and cultivated in a plant growth chamber under the common background conditions of $21^{\circ} \mathrm{C}$ with a 12:12 light:dark photoperiod. The lights used for the culture are provided by monochromatic LED with the center wavelength of $456 \mathrm{~nm}, 512 \mathrm{~nm}$ and $656 \mathrm{~nm}$, respectively. The light intensity can be adjusted from 20 $\mu \mathrm{mol} \cdot \mathrm{m}^{-2} \cdot \mathrm{s}^{-1}$ to $80 \mu \mathrm{mol} \cdot \mathrm{m}^{-2} \cdot \mathrm{s}^{-1}$ by changing the distance between the light source and vessel. The spectra of light sources are measured by PR-650 spectrophotometer/spectrocolorimeter, as shown in Figure 1.

\subsection{Method of Measurement}

For researching the growth condition of Skeletonema costatum, a $50 \mu \mathrm{L}$ algal sample is fetched from each flask everyday, and then supported by a glass slide. The numbers of algal cell are counted under optical microscope, and cell number countings are repeated for at least three times. The specific growth rate $\mu$ was calculated during the exponential growth period by $[18,19]$

$$
\mu=\frac{\ln N_{2}-\ln N_{1}}{t_{2}-t_{1}}
$$

where $N_{1}$ and $N_{2}$ are cell numbers on days $t_{1}$ and $t_{2}$, respectively.

\section{Results and Discussion}

\subsection{Effects of Light Intensity and Light Quality on the Growth of Skeletonema costatum}

Firstly, we study the effect of blue light on the growth rate of Skeletonema costatum. Skeletonema costatum strain culture is maintained in conditions as mentioned above until the end of the exponential phase. The typical light intensity used are $20,30,40,45,50,60$ and $80 \mu \mathrm{mol} \cdot \mathrm{m}^{-2} \cdot \mathrm{s}^{-1}$. For all light intensities, the Skeletonema costatum has an exponential growth phase in seven days, as is shown in Figure 2(a). (Considering that the cell cycle of Skeletonema costatum is about five days [12], we pay our attentions to the data in the first seven days). For different light intensities, the

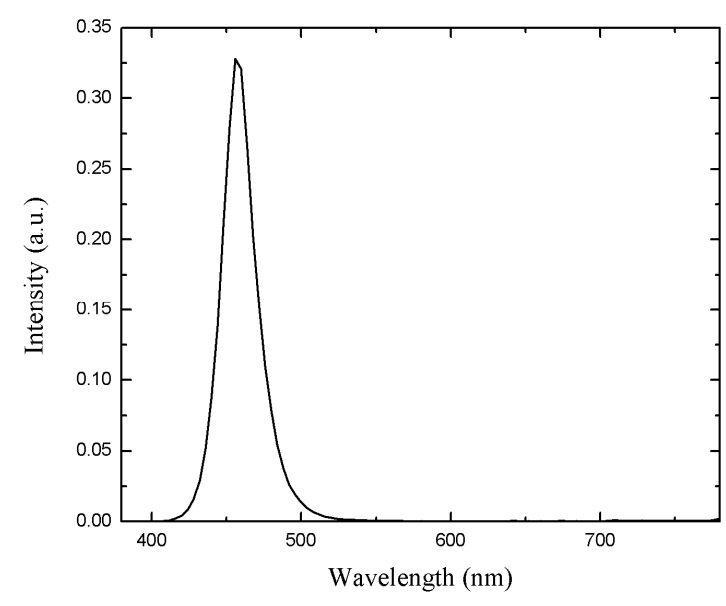

(a)

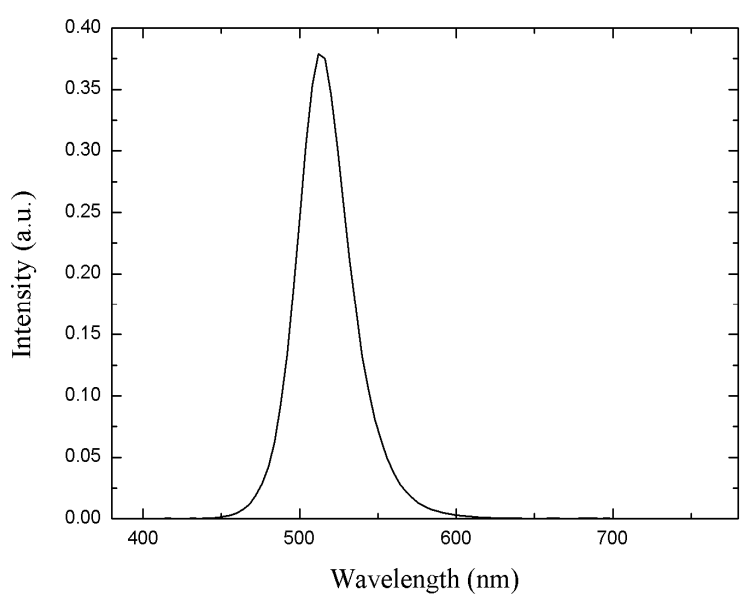

(b)

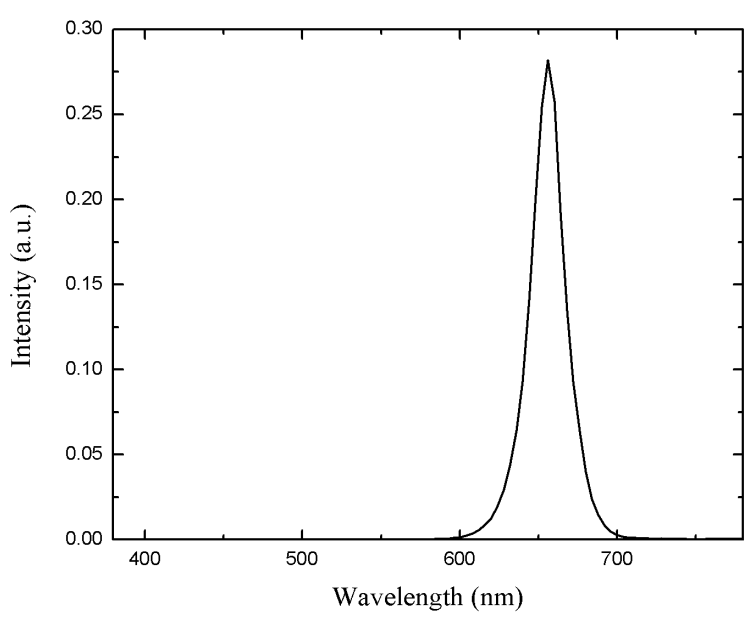

(c)

Figure 1. Spectra of three kinds of LED illuminants. (a) Blue; (b) Green; (c) Red.

growth of Skeletonema costatum is significantly different, especially after two days. Based on the cell number, we can calculate the growth rates under different light intensities using Equation (1). As is shown in Figure 2(b), the 


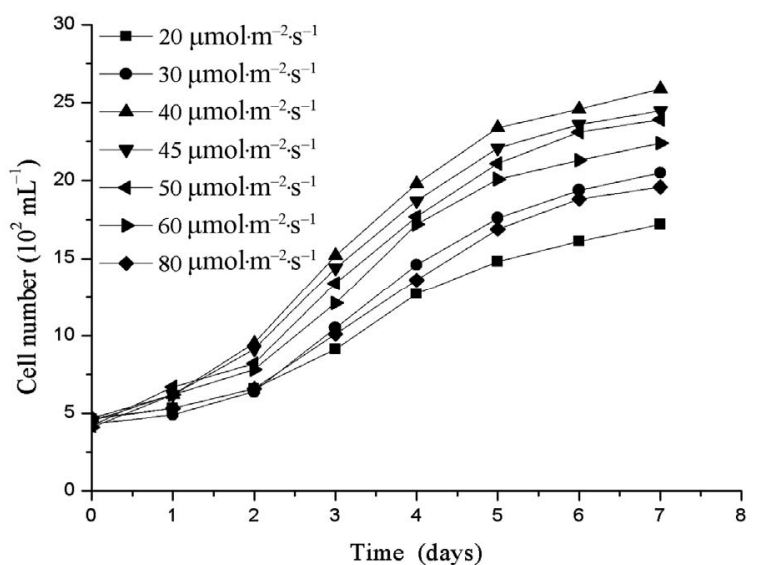

(a)

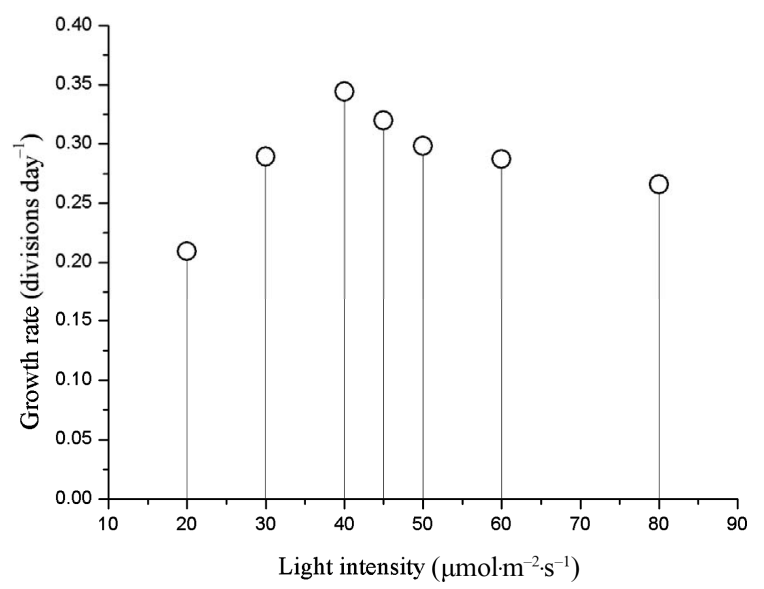

(b)

Figure 2. (a) The growth curve of Skeletonema costatum under blue light; (b) Growth rate of Skeletonema costatum under blue light.

growth rates increase with the increasing light intensity from 20 to $40 \mu \mathrm{mol} \cdot \mathrm{m}^{-2} \cdot \mathrm{s}^{-1}$, the maximum growth rate is observed at $40 \mu \mathrm{mol} \cdot \mathrm{m}^{-2} \cdot \mathrm{s}^{-1}$ (Figure 2(b)). When the light level exceeds $40 \mu \mathrm{mol} \cdot \mathrm{m}^{-2} \cdot \mathrm{s}^{-1}$, the growth rates of Skeletonema costatum gradually decrease, which means the saturated light intensity of Skeletonema costatum under blue light is about $40 \mu \mathrm{mol} \cdot \mathrm{m}^{-2} \cdot \mathrm{s}^{-1}$.

When the Skeletonema costatum are cultured under green light, the effect of the wavelength on the growth of the microalgae is not significant in the first two days (Figure 3(a)), and then it goes significantly different after two days. Growth response curves as a function of intensity for Skeletonema costatum are shown in Figure 3(b). The growth rates of Skeletonema costatum increase when light intensity increases from 20 to $50 \mu \mathrm{mol} \cdot \mathrm{m}^{-2} \cdot \mathrm{s}^{-1}$, and then decreases beyond $50 \mu \mathrm{mol} \cdot \mathrm{m}^{-2} \cdot \mathrm{s}^{-1}$. The highest growth rate of Skeletonema costatum is 0.3006 at 50 $\mu \mathrm{mol} \cdot \mathrm{m}^{-2} \cdot \mathrm{s}^{-1}$.

By the same method, we study the cell numbers and growth rates of Skeletonema costatum under red light, as

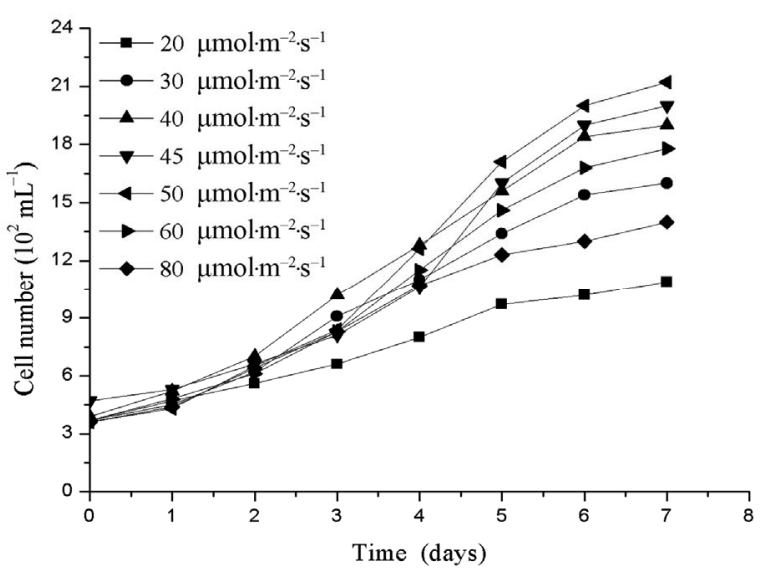

(a)

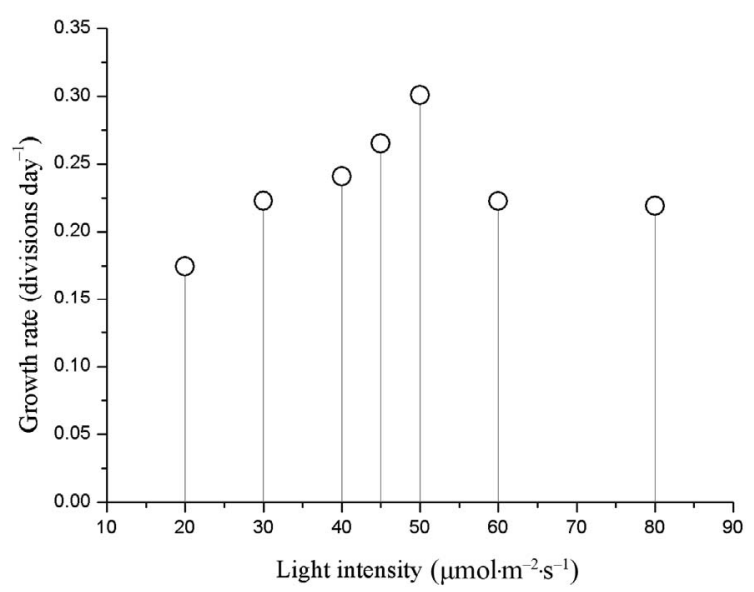

(b)

Figure 3. (a) The growth curve of Skeletonema costatum under green light; (b) Growth rate of Skeletonema costatum under green light.

is shown in Figures 4(a) and (b). The growth rates of Skeletonema costatum increase with the increasing light intensity from 20 to $45 \mu \mathrm{mol} \cdot \mathrm{m}^{-2} \cdot \mathrm{s}^{-1}$. When exceeds this light intensity range, the growth rates gradually decrease. The maximum and minimum growth rates of Skeletonema costatum are 0.1953 at $20 \mu \mathrm{mol} \cdot \mathrm{m}^{-2} \cdot \mathrm{s}^{-1}$ and 0.3212 at $45 \mu \mathrm{mol} \cdot \mathrm{m}^{-2} \cdot \mathrm{s}^{-1}$, respectively. The saturated light intensity of Skeletonema costatum under red light is about $45 \mu \mathrm{mol} \cdot \mathrm{m}^{-2} \cdot \mathrm{s}^{-1}$.

Results above show that when cells are exposed to blue, green or red light, the growth conditions of Skeletonema costatum are greatly influence by different light wavelength. For three kinds of monochromatic light, the growth rates of Skeletonema costatum are significantly different. The growth rate under blue light is larger than under green and red light until it reaches saturation light intensity. In blue light condition, the saturation light intensity is about $40 \mu \mathrm{mol} \cdot \mathrm{m}^{-2} \cdot \mathrm{s}^{-1}$, which below the value of saturation light intensity of the green $\left(50 \mu \mathrm{mol} \cdot \mathrm{m}^{-2} \cdot \mathrm{s}^{-1}\right)$ and red light $\left(45 \mu \mathrm{mol} \cdot \mathrm{m}^{-2} \cdot \mathrm{s}^{-1}\right)$. 


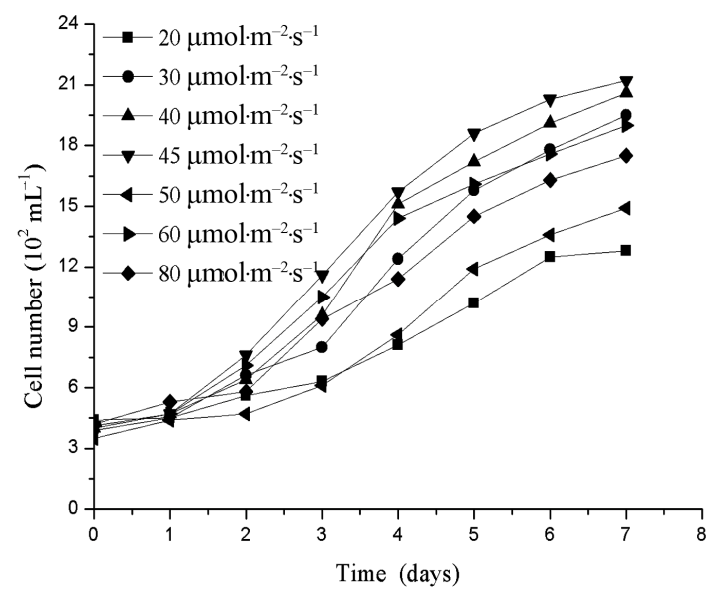

(a)

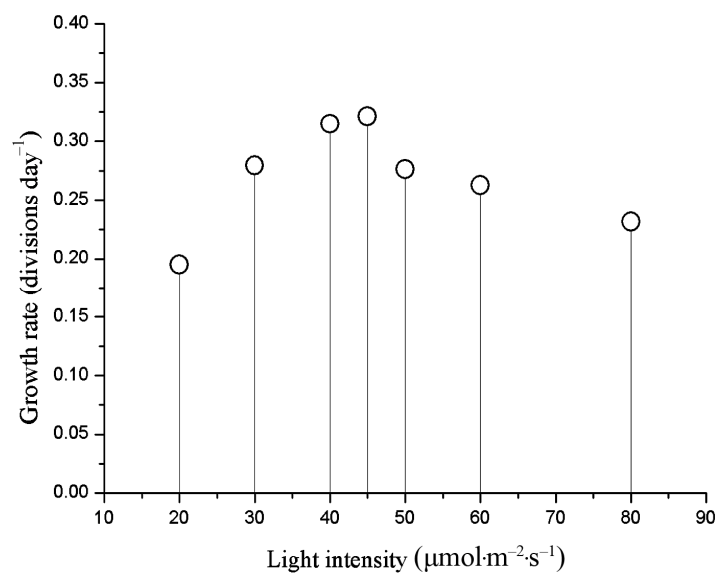

(b)

Figure 4. (a) The growth curve of Skeletonema costatum under red light; (b) Growth rate of Skeletonema costatum under red light.

\subsection{The Relationship of Spectrum Absorption Coefficient and Growth Rate, Saturated Light Intensity}

Spectrum absorption coefficient represents the quantum efficiency of the light photosynthetic effective quantum flux absorbed by microalgae, and it further reflects the efficiency of the light to promote the growth of microalgae. In this work, we estimated the relationship between the growth rates and spectrum absorption coefficient using the equation by [20]:

$$
A_{\eta}=\frac{\sum_{400}^{700} \lambda \phi(\lambda)\left[1-10^{-O D(\lambda)}\right] \Delta \lambda}{\sum_{380}^{780} \lambda \phi(\lambda) \Delta \lambda}
$$

where $\lambda$ is wavelength, $\Delta \lambda$ is wavelength interval, $\phi(\lambda)$ is relative spectrum power density, and it is provided by the spectra of light sources. $O D(\lambda)$ is absorbance, and it can be obtained from the absorption spectrum of microalgae, as is presented in Figure 5.
Based on Equation (2), it is now possible to estimate the spectrum absorption coefficient of Skeletonema costatum in different lights. Spectrum absorption coefficient of blue light is 0.0913 (Figure 6), it is larger than that of red light and green light ( 0.0871 and 0.0868 , respectively). With the certain photosynthetic available quantum flux density, the growth rates of Skeletonema costatum is the highest under blue light and the lowest under green light within saturated light intensity. As a result, we can conclude that the saturated light intensity decreases and the rowth rate increases with the increasing of spectrum absorption coefficient.

\section{Conclusion}

In conclusion, effects of light intensity and quality of three kinds of LED monochromatic light (blue, green, and red) on the growth of Skeletonema costatum are investigated. Results indicate that Skeletonema costatum prefer blue and red light to green light and the saturated light intensity is significantly different under three monochromatic

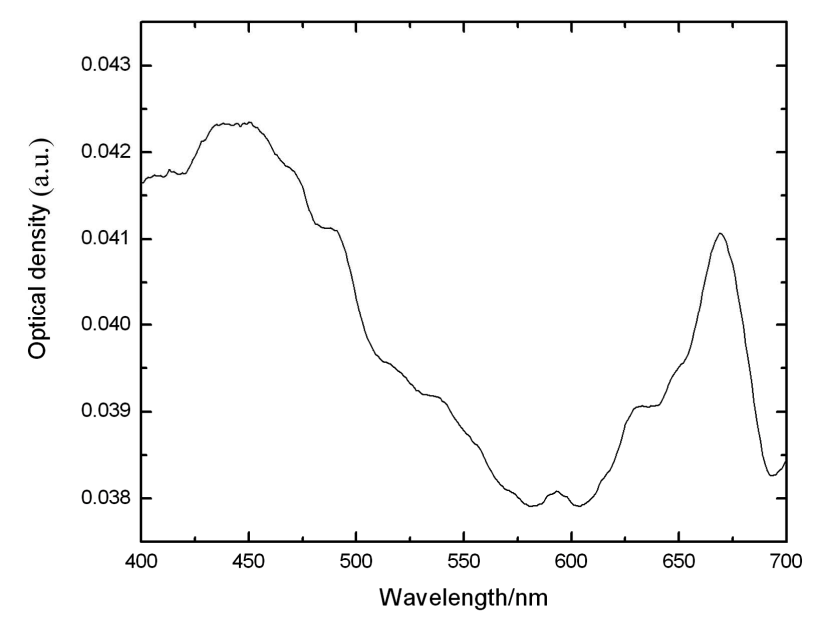

Figure 5. Absorption spectrum of Skeletonema costatum.

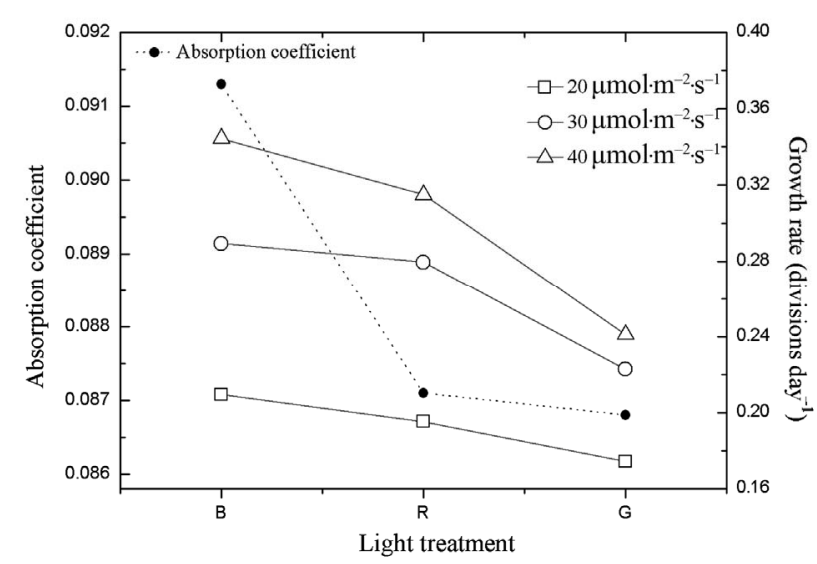

Figure 6. The relationship of Spectrum absorption coefficient and growth rates under blue, green and red light. 
lights. Based on the theory of quantum energy level transition, we analysis the results of the experiment and conclude that the wavelength of the light and the corresponding spectrum absorption coefficient play important roles in the energy level transition of molecular photosynthesis. For further illustrating the role of light in the growth condition of Skeletonema costatum, we obtain the relationship between spectrum absorption coefficient and growth rate or saturated light intensity. In blue light condition, the value of saturated light intensity is the least (40 $\left.\mu \mathrm{mol} \cdot \mathrm{m}^{-2} \cdot \mathrm{s}^{-1}\right)$, but the spectrum absorption coefficient is the largest $\left(A_{\eta}=0.0913\right)$. In green light condition, the value of saturated light intensity is the largest (50 $\left.\mu \mathrm{mol} \cdot \mathrm{m}^{-2} \cdot \mathrm{s}^{-1}\right)$, but the spectrum absorption coefficient is the least ( $\left.A_{\eta}=0.0868\right)$. Hence, saturated light intensities are negative correlation with the spectrum absorption coefficient. It also shows that within the saturated light intensity and the same photosynthetic available quantum flux density, the growth rates is the largest under blue light and the least under green light, therefore, the growth rates of Skeletonema costatum are positive correlation with the spectrum absorption coefficient. Results presented in this work may offer valuable references for estimating the effect of light wavelength on the growth condition of Skeletonema costatum and understanding the mechanism of the red tides occurrence.

\section{Acknowledgements}

This research is funded by Natural Science Foundation of Shandong Province (No. ZR2010DM009) and the Fundamental Research Funds for the Central Universities (No. 201113011).

\section{REFERENCES}

[1] T. J. Smayda, "Harmful Algal Blooms: Their Ecophysiology and General Relevance to Phytoplankton Blooms in the Sea," Limnology and Oceanography, Vol. 42, 1999, pp. 1137-1153. doi:10.4319/10.1997.42.5 part 2.1137

[2] J. S. Xu, "Offshore Shrimp Pond and Red Tide," Marine Press, Beijing, 2003

[3] M. J. Zhou and M. Y. Zhu, "Progress of the Project Ecology and Oceanography of Harmful Algal Blooms in China," Advances Earth Science, Vol. 21, No. 7, 2006, pp. 673-679.

[4] H. L. Cheng, S. H. Lv, C. S. Zhang, et al., "A Survey on the Red Tide of Prorocentrum donghaiense in East China Sea," Ecologic Science, Vol. 25, No. 3, 2006, pp. 226230.

[5] Y. S. Lee, "Factors Affecting Outbreaks of High Density Cochlodinium polykrikoides Red Tides in the Coastal Seawaters around Yeosu and Tongyeong, Korea," Marine Pollution Bulletin, Vol. 52, No. 10, 2006, pp. 1249-1259. doi:10.1016/j.marpolbul.2006.02.024

[6] Y. Li, D. J. Li, J. L. Tang, et al., "Phytoplankton Distri- bution and Variation in the Yangtze River Estuary and Its Adjacent Sea," Environmental Science, Vol. 28, No. 4, 2007, pp. 719-729.

[7] Y. J. Sheng and D. H. Chen, "Effect of Different Light Cycle on the Growth of P. Millirod Algae and Green Millirod Algae," Journal of Lake Science, Vol 16, No. 3, 2004, pp. 21-25.

[8] R. Y. Sun, B. Li, G. Y. Zhu, et al., "Ordinary Ecology," Higher Education Press, Beijing, 1993.

[9] W. Wang and J. M. Lin, "Light-Dependent Control and Development of Algae," Chinese Bulletin of Botany, Vol. 17, No. 5, 1998, pp. 31-39.

[10] H. B. Seung, S. J. Shimode, Tomohiko, et al., "Growth of Dinoflagellates, Ceratium furca and Ceratium fusus in Sagami Bay, Japan: The Role of Temperature, Light Intensity and Photoperiod," Harmful Algae, Vol. 7, No. 2, 2008, pp. 163-173. doi:10.1016/j.hal.2007.06.006

[11] H. Mao, H. Xu and Z. P. Liu, "Effects of Water Temperature, Illumination, and $\mathrm{pH}$ on the Growth of Chaetoceros curvisetus," Ecological Science, Vol. 26, No. 5, 2007, pp. 432-436.

[12] B. Y. Sun, S. K. Liang, C. Y. Wang, et al., "Role of Irradiance on the Seasonality of Skeletonema costatum Cleve Blooms in the Coastal Area in East China Sea," Environmental Science, Vol. 29, No. 7, 2008, pp. 1849-1854.

[13] P. Yu, Q. Q. Zhang and X. L. Wang, "Effects of Temperature and Irradiance on Growth of Two Strains of Marine Diatoms," Marine Environmental Science, Vol. 25, No. 1, 2006, pp. 38-40.

[14] J. B. Chou, L. H. Hu, S. Z. Lin, et al., "Study on the Productive Culture of Skeletonema costatum Goreville," Shandong Fisheries, Vol. 23, No. 6, 2006, pp. 27-29.

[15] W. Wang, "Effect of Light Quality on Growth and Biochemical Compositions of a Diatom Biddulphia sinensis," Journal of Wuhan Botanical Research, Vol. 17, No. 3, 1999, pp. 197-200.

[16] Y. W. Shen, Z. Y. Zhu and Y. D. Liu, "Effects of Different Light Quality on Richelia sinica," Acta Hydrobiologica Sinica, Vol. 23, No. 3, 1999, pp. 285-287.

[17] Y. Wu and L. Gu, "Study on the Growth and the Light Bioreactor Intracellular Polysaccharide of Two Kinds of Microalgae," Biotechnology, Vol. 14, No. 3, 2004, pp. 5960.

[18] S. Nagasoe, D.-I. Kim, Y. Shimasaki, et al., "Effects of Temperature, Salinity and Irradiance on the Growth of the Red Tide Dinoflagellate Gyrodinium instriatum Freudemthalet Lee," Harmful Algae, Vol. 5, No. 1, 2006, pp. 20-25. doi:10.1016/j.hal.2005.06.001

[19] J. L. Mouget, P. Rosa and G. Tremblin, "Acclimation of Haslea ostrearia to Light of Different Spectral Qualities Confirmation of 'Chromatic Adaptation' in Diatoms," Journal of Photochemistry and Photobiology B: Biology, Vol. 75, No. 1-2, 2004, pp. 1-11. doi:10.1016/j.jphotobiol.2004.04.002

[20] A. J. Mao and J. Wang, "Calculation and Application of Photosynthetic Photon Flux Density," Periodical of Ocean University of China, Vol. 36, 2006, pp. 151-155. 